\title{
Early adolescent bystanders' experiences of school bullying in a South African school
}

\section{Segun Emmanuel Adewoye}

Department of Educational Psychology, Faculty of Education, University of Pretoria, Pretoria, South Africa adewoyesegunemmanuel@gmail.com

https://orcid.org/0000-0001-8323-0933

\section{Annelize du Plessis}

Department of Humanities Education, Faculty of Education, University of Pretoria, Pretoria, South Africa annelize.duplessis@up.ac.za

https://orcid.org/0000-0002-7134-5028

(Received: 14 March 2021; accepted: 23 September 2021)

\section{Abstract}

Bystanders of school bullying are relatively under-researched in the literature on bullying because most studies in this area focus primarily on bullies or on the direct victims of bullying. In this study, we aimed to explore the lived experience of early adolescent bystanders who witnessed bullying in a South African school. We followed a qualitative research approach and adopted a phenomenological research design. We purposefully selected 10 early adolescent bystanders to participate in the study. We recorded the interviews that were then transcribed. We used inductive thematic analysis to analyse the qualitative data. The findings of this study revealed the various emotional and behavioural reactions of bystanders to witnessing school bullying. We recommend that anti-bullying programs be included in the curriculum so that teachers and school psychologists can emphasise the negative impacts of bullying that include psychological, educational, and emotional consequences on everyone who is exposed to it.

Keywords: early adolescent, bystanders, emotional and behavioural consequences, school bullying, South African school context

\section{Introduction}

Bullying at school, an aggressive behaviour considered to be destructive, can be interpreted as a symptom of an unhealthy school climate (Ttofi \& Farrington, 2011). Several definitions of bullying are prominent in the literature. For instance, Gaffney et al., (2021) defined bullying as a ubiquitous form of aggression directed towards the victim that is intended to cause fear or inflict pain. In similar vein, the South African Human Rights Commission 
(2008, p. 6) defined bullying as an aggressive behaviour consisting of repeated physical, verbal and non-verbal acts displayed repeatedly over a period of time by one person against another that are intended to inflict injury or discomfort and occur in a relationship marked by a real or perceived imbalance of power.

South African school learners have reported the prevalence of bullying in schools (Adewoye \& Du Plessis 2021; Tustin et al., 2014). The Youth Research Unit at the University of South Africa reported that in 2012,34.4\% of learners in schools sampled in Gauteng confirmed that they had been victims of bullying and $67.7 \%$ of participants reported that bullying had increased in the past two years preceding the report (Lass \& Boezaart, 2014). The increasing rate of bullying in South African schools could be explained as being in response to the many violent acts in South African communities with which the in-school adolescents are conversant and that are mimicked in school contexts (Timm \& Eskell-Blokland, 2011).

The prevalence of school bullying is not a concern unique to South Africa; it is, rather, considered a worldwide phenomenon (Valdebenito et al., 2018). For instance, in a recent meta-analysis of 80 international studies, it was revealed that the prevalence rate of bullying perpetrations is $34.5 \%$ while bullying victimization is $36 \%$ (Modecki et al., 2014). Similarly, another survey revealed that worldwide, nearly $50 \%$ of school learners were involved in school bullying either as bystanders, perpetrators, or direct victims (Zych et al., 2017).

Bullying victimisation has been linked to a number of negative consequences that include drug use, self-harm, criminal behaviour, sleeping problems, violence, suicidal ideation, and poor academic performance (Bakken \& Gunter, 2012; Bender \& Losel, 2011; Esala, 2013; Geel et al., 2016; Holt et al., 2015). For instance, victims of bullying in schools in South Africa were said to be more likely to experience negative behavioural and emotional responses (Barhight, et al., 2013; Knauf, et al., 2018). Boyes et al., (2014) reported that 70\% of learners in Grades 4 to 7 in South African schools, who experienced bullying at school, exhibit symptoms of trauma.

The research findings of Gini \& Pozzoli (2013) revealed that victims of bullying experience low social and emotional wellbeing and also engage in riskier health behaviours. Van Dam et al. (2012) found from their studies that victims of bullying experience poor social adjustment and a higher level of loneliness than do children not involved in bullying. Research has indicated that bullies are likely to become accustomed to the use of violence and aggression to solve problems. Learners who engage in bullying behaviour tend to gain and maintain dominance in an aggressive way and often lack any sense of empathy (Rivers et al., 2009). Ttofi et al. (2012) established that the consequence of bullying behaviour for the bully is that they try to extend their bullying behaviour into the wider world including cyberspace and also into the workplace where bullying may not be tolerated and this might make them end up committing criminal offences and, consequently, facing or experiencing imprisonment.

A preliminary observation revealed that bullying has continually been described as a collective process involving not just the bully and the victims, but also a group of passers-by or observers who are classified as bystanders (Salmivalli, 2014). In a study by Polanin et al. 
(2012), bystanders were found to be present at $85 \%$ of bullying episodes. Bystanders are an important but often overlooked group beyond the bully-victim dyad who might also be affected by bullying incidents that they witness (Rivers et al., 2009; Salmivalli 2014).

Midgett and Doumas (2019) noted that there is a likelihood that witnessing a traumatic event might make a bystander think differently about themselves and the world. Such negative thoughts and feelings might stem from three probable causes: psychological re-victimisation; acquiring indirect co-victim status because of deep feelings of empathy for the direct victims; and being fearful of becoming the next victim (Rivers et al., 2009). Hutchinson (2012) further asserted that the fear of subsequent direct victimisation, psychological revictimization, and experiencing cognitive dissonance may lead to higher levels of trauma, sensitivity, distress, and depression for bystanders. Since cognitive dissonance occurs when one's beliefs and attitudes clash with one's behaviour, a bystander to bullying may experience this in a scenario in which they believe that bullying is not good, and they want to intervene on behalf of the victim but cannot do so because they are afraid of becoming the next target (Midgett \& Doumas, 2019). In like manner, Ttofi \& Farington (2011) indicated that as a result of learners witnessing bullying as bystanders, they may feel insecure at school and this may result in their having divided attention in class, suffering low self-esteem and loneliness, having low academic achievement, engaging in truancy from school, and using drugs.

Despite indications that witnesses of bullying behaviour can also be negatively affected and might be even more likely to report symptoms of psychological stress like depression, anxiety, and insecurity than the direct victims of bullying themselves (Deng et al., 2021; Ttofi et al., 2016), research on bystanders is yet to receive full attention (Carrera et al., 2011). According to Salmivali (2014), the bystander is relatively under-researched in bullying literature because most studies on bullying focus primarily on bullies or on the direct victims of bullying. This is because direct victims of bullying are thought to bear the larger brunt of the impacts of bullying because physical harm perpetrated against direct victims is apparent in the visible signs of injury (Englander 2013). Consequently, direct victims of bullying get immediate attention often because of such visible signs of injury (Rigby \& Johnson 2006) while bystanders who might sustain emotional scars from the experience of witnessing peer victimisation in schools are probably the most overlooked when attention is given to problems related to bullying (Rigby \& Johnson, 2006; Darney et al., 2013).

Since bullying has been described as a group phenomenon (Salmivalli, 2014), and bully, victim, and bystander co-exist in the school setting and in the wider community, bystander experiences of school bullying also warrant more attention (Gini \& Pozzoli 2013; Tsang et al., 2011). This is particularly pertinent since bystanders form the majority of the participants in school bullying events and studies have shown, as mentioned above, that bullying can have devastating negative effects on all parties involved (Baldry, 2017; Lambe et al., 2017). It is clear that further research is required to fully comprehend bystanders' experiences of bullying as Howard et al. (2014) have pointed out.

We know of only a few qualitative research studies (Juan et al., 2018; Mncube \& Chinyama, 2020; Moosa, 2020) that have focused on the bystander experience of school bullying in the 
context of South African schools. This led us to initiate this study to give voice to early adolescent bystanders, better understand their lived experiences of bullying, and add to the professional literature on this subject. Almost all existing bystander research was conducted with adult participants using quantitative methods and little is known about the experience of early adolescent bystanders who witness bullying at school (Howard et al., 2014).

This study is intended to be a starting point in the genesis of conceptualising and understanding how witnessing bullying might affect the emotional and psychological wellbeing of early adolescent bystanders with a view to informing proactive and reactive approaches that South African schools could adopt to buffer these effects. In particular, the research question addressed in this study was

- What is early adolescent bystanders' experience of school bullying in the context of a South African school?

\section{Methods}

\section{Research approach, paradigmatic perspective, and design}

Following Creswell (2014) we used a qualitative research method for this research study. For Basit (2010), using a qualitative approach to research studies is appropriate for one that intends to draw its findings from participants' perspectives. We adopted this approach because we wanted to uncover many different perspectives, provide complete accounts, and thus offer detailed views of early adolescent bystanders' experiences of school bullying.

The philosophical assumption that underpins our study led us to choose an interpretivism paradigm — one that is aimed, necessarily, at comprehending the world through the perspective of people's lived experiences (Morgan \& Pretorius, 2013; Sefotho, 2015; Silverman, 2011).

We adopted a phenomenological research design for this study because its objective was to analyse the phenomenon of bystander bullying along with its social and contextual significance. This phenomenon is difficult to quantify, and new insights are required, so, in agreement with Creswell (2014) that a phenomenological design should be used to analyse a phenomenon as the participants narrate it, we saw the purpose of our study being to listen, comprehend, and interpret the meaning bystanders ascribed to their experience of school bullying.

\section{Procedure}

We adopted a convenience sampling technique to select the research site, a school located in Mamelodi, Gauteng, South Africa, at which we planned to select our participants. We assumed that the proximity of the school to participants' homes would further motivate them to attend the interview sessions. 
We visited the school we had identified, and the principal confirmed that learner to learner bullying was not only rampant in the school, but learner to teacher bullying was also on the increase and expressed his willingness to allow us to conduct the research study here. We scheduled a meeting with the prospective participants after obtaining the required ethical clearance, to explain the project and obtain the requisite written assent from them and consent from their parents/guardians. We explained the objectives of the research as well as the potential gains of participating in it.

We presented a detailed document prior to starting the interviews to inform the participants of the aim of the research, the nature of the interviews we planned to hold, and the types of questions they could expect. We established a good rapport with the participants as a result of this. In addition, we assured them that their personal information would not be revealed to anyone and that we would use pseudonyms to ensure this confidentiality. We ensured that the participants had a proper understanding of their involvement in the research before they agreed to participate in it.

\section{Participants and sampling strategies}

Learners who had not been a direct victim of bullying but had witnessed bullying in school were identified through their responses to an invitation letter to participate in a research project. To be included according to our criteria, the learner had to be attending the school that was the research site, had to be an early adolescent ranging in age from 11 to 13 years, had to have been a bystander to bullying, and had to be in Grade 6 or 7. As a result, all learners in Grades 6 and 7 who were believed to match all the inclusion requirements were included in the first phase of the sampling process.

The interviews took place after school to prevent the disruption of school activities. Participants were interviewed in a classroom setting because we believed that this would allow them to respond in a natural and honest manner. During the first phase, 60 learners, spread between two groups, were instructed to write about the bullying situations they had witnessed at school. Both groups were given the same set of instructions. Of the 60 stories collected, 25 did not fit one of the inclusion requirements that stated that participants should not have been a direct victim or perpetrator of bullying but should have witnessed bullying in school. Consequently, learners who indicated in their stories that they were direct victims or that they had bullied others were excluded. The final 10 participants were chosen purposefully for interviews based on the level of information and self-reflection evident in their written accounts of the episodes of bullying they had witnessed. Of the 10 participants, eight were girls and two were boys.

\section{Data collection instrument}

An interview is a key source of data collection in a qualitative phenomenological study as Yin (2016) has pointed out. Consequently, we held a face-to-face individual semi-structured interview to investigate and describe each participant's experiences as a bystander of school bullying. We recorded the individual interviews with the permission of the participants and 
the consent of their parents. As a back-up, we wrote notes as well. We used field notes and a reflective research diary to record our observations while we were interacting with the participants during the interviews. Each interview session lasted for about 45 minutes. We asked all the participants the same set of open-ended questions. In line with Burton \& Jones (2008) we had prepared these using information from our literature review and from the purpose and objectives of this study along with its research question.

\section{Ethical considerations}

In conducting this study, we made certain that all ethical procedures were followed. We received ethical approval from the University of Pretoria's Faculty of Education's Ethics Committee, as well as authorization from the Gauteng Department of Education to work and conduct research in the school. Informed assent from participants in written form were collected, as well as a consent letter of permission from the parents or legal guardians of the learners who took part in the study. The letter covered issues such as confidentiality, voluntary participation, research location, and purpose of the study. In addition to observing the above ethical principles, we engaged the service of an independent registered educational psychologist to assist with a debriefing session at the end of the data collecting session since some participants may have been traumatized by the memory and/or narration of the bullying episodes they had witnessed. The parents of participants were adequately informed and granted access to the educational psychologist for further engagement when necessary.

\section{Data analysis and interpretation}

We used inductive thematic analysis to analyse the qualitative data that included the transcriptions of the audio recordings of the interviews and our notes. According to Braun and Clarke (2006), inductive thematic analysis is a frequently used type of qualitative research analysis the goal of which is to identify, investigate, and record patterns in data. In order to establish and create meaningful patterns, we coded the data. This included a) becoming familiar with the data, b) generating initial codes, c) searching for themes, d) reviewing the themes, e) defining and naming the themes, and f) writing up the results.

\section{Trustworthiness of the study}

We ensured the trustworthiness of the study by member checking that meant getting feedback on the data, on our interpretation of it, and the conclusions from the participants themselves (see Creswell, 2014). We provided opportunities for the participants to clear any doubts they had about the research process by allowing them to ask questions.

\section{Findings}

We presented the findings according to the themes and subthemes generated from the data. 


\section{Theme 1: Willingness to intervene}

The data revealed the reactions of participants to witnessing bullying at school. Participants in this study demonstrated a willingness to intervene as part of their reaction to such witnessing. The participants were asked to describe the bullying incidents they witnessed and to state if they had intervened or not to help the victims when they witnessed bullying. Participant 1 responded by saying, "I did feel like helping her and telling the bully not to hit her." Most of the participants showed an intention to defend the victims in a bullying situation if they had the power. For instance, Participant 2 said, "Yes, I do feel like I can intervene when I witness bullying. When it happens in front of my eyes, I do wish I can intervene." Participant 5 expressed a similar intention in her response by saying, "I feel like that to go and help the victim but if I can't, I go to tell the teacher to intervene."

Participants felt sympathetic concern for the victims. They did understand that bullying is wrong and wished they could intervene on behalf of the victims. Participant 9 explained, "I feel like I can tell the principal or my mother, but I am afraid because if I tell them, the bully is going to beat me." Participant 6 noted that although he felt pain for the victim, the fear of being bullied overshadowed his intention to intervene. He said, "Yes, I want to, but I am afraid because myself too they can bully me I am scared because they might beat me or bully me just like they are doing to the victim."

From all indications, it appeared that bystanders were trapped in the dilemma of being willing to defend victims in a bullying situation but also conscious of their own safety and vulnerability.

\section{Theme 2: Self-blame and feeling guilt for not being able to intervene.}

Almost all the participants in this study apportioned self-blame and reported feelings of guilt and disappointment for not being able to intervene to help the victims of bullying. Participant 2 said,

Yes, I do feel guilty very much guilty when I witness bullying. Sometimes I even wish I could go and tell the principal but when I think that the bully can even come back to me, I don't go, and I feel guilty.

Participant 7 expressed disappointment at herself when she was asked to describe how she felt about not being able to intervene when she witnessed bullying. She said, "I don't feel good at all because if I couldn't help the victim and she get injured, to me is like I failed her." Participant 5 believed that she betrayed the trust her friend, who was bullied, had in her for not being able to intervene on her behalf when she witnessed this. Consequently, she blamed herself and thought she was the cause of the victimisation her friend suffered. She declared, "Yaa I do blame myself. I wish I could have helped or called somebody, but I couldn't, so I blame myself."

We noted that most of the participants felt indebted to the victims for not having defended them when they witnessed the bullying. Following our observation, we remarked in our 
research journal, "Following the individual semi-structured interviews conducted with participants, we observed that most participants engaged in personalisation which led to attribution of self-blame and trauma related guilt in their reactions to witnessing bullying." (Reflective Journal 4/9/2019)

The response of Participant 6, while narrating how he felt about himself for not being able to defend victims whom he witnessed being bullied confirmed our observation when he said, "Yes, I feel bad and guilty, and I do blame myself." It would appear that bystanders experience self-blame and feelings of guilt if they take personal responsibility or think that they are the sole cause of the bullying they witnessed because they were unable to do anything to stop it.

\section{Theme 3: Difficulties in concentration because of psychological re-victimisation}

Most participants in this study reported that they experienced difficulties in paying attention in class because of co-victimisation or psychological re-victimisation. At several points throughout the interview, some participants mentioned their challenges. Participant 2 said, "It affects me a lot when I am in class. Sometimes even when I am writing a test instead of thinking about the test that I am writing, I start thinking about the bullying that I witnessed." Participant 9 added, "I can't concentrate because every time when the teacher is teaching, my mind is thinking that they will bully me. I can't concentrate." Participant 4 explained, "I can't concentrate when Mam is teaching. I can't even hear when the other kids are answering the Mam because I am thinking about the bullying that I witnessed." Participant 6 said,

My concentration is not in the class because I feel like those people are there. They want to come and take my pen. Yes, I get carried away when I think about the bullying because I feel like it is me that is being bullied.

Participant 10 confirmed that sometimes she would forget that she was in class even when the teacher was teaching because she is absent minded. She said,

It does affect me even when my teacher is teaching me my mind goes off sometimes even if she asks me a question, I will just be looking at her because I am not concentrating because I am thinking about the bullying that I witnessed.

It would appear that the anxiety caused by the fear of subsequent direct victimisation contributes to bystanders' emotional insecurity and uncertainty and this makes concentration on academic tasks and learning at school difficult.

\section{Theme 4: Negative emotions and behaviours}

Participants generally expressed negative emotions and behaviours in reaction to witnessing bullying. Participant 4 described her experience when she said, 
I feel very sad when I witnessed bullying because it is not the first time that this boy bully learners. Even last year he did the same thing, and they give him warning but he is still bullying learners even now. So, I am scared.

Rivers et al. (2009) reported that the fear of subsequent direct victimisation has the potential to contribute to bystanders' negative behavioural and emotional responses to witnessing bullying. Participant 8 confirmed this assertion by saying,

I feel scared because those bullies might come to me or might go and beat another person. I feel bad because sometimes I have bad dreams. I dream like it is me that they are bullying. It disturbs me a lot in my sleep.

Thinking about and fearing becoming the next victim might also produce feelings of anger, sadness, sleeplessness, restlessness, mistrust, frustration, and moodiness. This is confirmed in the reactions of Participant 7 when she said, "I feel so restless because witnessing bullying make me to feel so sad because bullying is not good at all. It makes me feel down because I can't do anything at school." When asked how witnessing bullying in school generally affects her mood, Participant 3 said, "I don't trust anyone because I feel like they, too, are part of those who are busy bullying learners."

\section{Theme 5: Insecure feelings}

This theme reflected bystanders' concern about their vulnerability to bullying victimisation in terms of fear that led to insecure feelings. Thinking about and fearing being the next target of bullying, with its accompanying negative emotions such as anger, sadness, and restlessness diminished participants' ability to engage in learning activities even in a non-threatening school environment.

We asked the participants to describe how they feel about their safety in school after they witnessed bullying. They stated clearly that they feel insecure at school because they always think that they will be bullied as well. Participant 7 remarked, "I don't feel safe at all because I am scared that what if the bully come to me and challenge me that, 'Ehh you saw us.' So, I am not safe. That is why I don't feel safe." Participant 4 attested to feeling insecure in school as a result of fear that the bullies may target him next. He explained, "I am not sure if I can tell the teacher or principal because I feel scared that they can come and bully me."

It appeared that nearly all the participants in this study reported feelings of insecurity that stemmed, in part, from thinking about and fearing becoming the next victim after witnessing bullying. The school environment is expected to be a safe place where effective teaching and learning can take place. However, this is not the case for bystanders who constantly indulge in thoughts and fears of subsequent direct victimisation.

\section{Theme 6: School phobia}

During the individual semi-structured interviews conducted with the participants, we asked them if witnessing bullying affected their interest in going to school. Participant 1 disclosed, 
"Bullying make me to be afraid of school. Sometimes when my mother wakes me for school I am like 'No don't wake me up I don't want to go to school." Most participants stated that fear and anxiety became a daily part of their lives. Almost all the participants remarked that they dislike going to school for fear of being the next victim of bullying. Participant 2 made this assertion apparent when she said, "It does affect my likeness for school. Sometimes when I wake up I doubt if I should go to school or not because of this bullying." Participant 7 demonstrated her unwillingness to go to school as a result of fearing an attack and being harmed when she explained, "Yes, I do think about it the following day when I am supposed to go school. I get scared and say to myself that 'What if bullying happens to me?"'

The school plays a meaningful role in the socialisation of learners. However, if the school environment is hostile, learners may lose interest in going to school. Some participants claimed they like to be at home rather than in school. Participant 9 said,

Yes, I am afraid of school and I feel like I can go home but if I go home my mama will ask me why I come back. My mother will tell me that I must go back and report to the principal so that the principal can discipline that child but I am scared that after school, the bully can call me and said he want to talk to me only to find out that he wants to beat me.

Participant 5 confirmed her fear of going to school by saying, "When I wake up in the morning and think of going to school, I said 'No, I feel like not going to school every morning.",

It is evident that fear of being bullied negatively affected bystanders' response to going to school since most participants expressed a loss of interest in doing so. In addition, it seemed that the emotional distress caused by thinking about and fearing becoming the next victim of bullying created discomfort and unhappiness for participants even while they were at school. Participant 10 said,

I don't have happiness in school because I always feel like crying and I feel sad. I feel bad because sometimes I don't wish to come to school because of the bullying things and sometimes I am scared to come to school.

\section{Discussion}

The findings of this study reveal the various emotional and behavioural reactions of bystanders to witnessing school bullying. First, bystanders experienced cognitive dissonance because they believed that bullying was wrong, and they intended to intervene on behalf of the victim but their intention to do so did not translate into action because of the fear of becoming the next victim. Salmivalli (2014) explained that while most bystanders feel uncomfortable about not intervening and feel sympathetic towards victims, the fear of becoming the next target of bullying overshadows the feelings of willingness to intervene and defend the victims. In opposition to the findings of two previous studies (Padgett \& Notar, 2013; Polani et al., 2012) that point to bystanders' moral disengagement and lack of empathy, 
bystanders in this study did not reinforce bullying behaviour by laughing, cheering, or hailing the bullies. Instead, they demonstrated their disapproval of bullying behaviour even though they could not intervene.

Second, bystanders reacted by apportioning blame to themselves and felt guilty for not defending the victim. This finding echoes that of Hutchinson (2012) who noted that bystanders might experience an increased level of stress and guilt for not standing up to the bully on behalf of the victim.

Third, bystanders experienced difficulties in concentrating on academic tasks because of psychological re-victimisation. It follows that feeling emotionally and physically troubled as a result of fear of subsequent direct victimisation could impede learners' concentration on their studies. This finding confirmed the report of Midgett and Doumas (2019) that bystanders may be fearful and become distracted in school and that this makes concentrating on school activities difficult. After the bullying incidents were over, intrusive thoughts and images filled the minds of the bystanders and this caused them to identify with the pain and suffering of the victim. Consequently, the flashback of the bullying incidents they watched led to co-victimisation that, in turn, evoked negative emotions and behaviour such as anger, restlessness, worry, sadness, and shock. This finding resonated with Hutchinson's (2012) point of view that bystanders of school bullying are more likely to react to witnessing bullying with symptoms of secondary trauma stress like depression, anxiety, and insecurity than the bullied victims are. Furthermore, concerns about vulnerability in relation to being the next victim of bullying produced feelings of insecurity at school that negatively influenced bystanders' perception of school safety and their readiness to learn. This finding coincides with that of Strom et al. (2013) that learners in a negative school climate might lack the feeling of safety necessary for effective teaching and learning.

Last, fear of the unknown became a daily experience for bystanders in this study and this fear affected their interest in going to school. This finding indicated that if learners think the school environment is unfriendly, they may feel scared to go to school and consequently develop a phobic attitude towards school which could, in turn, impede school attendance. Berkowitz and Benbenishty (2012), as well as Bradshaw et al., (2013) noted that bystanders of school bullying may lose interest in going to school and are most likely to miss school as a result of feeling afraid or of anticipating direct bullying victimisation.

\section{Implications}

This research study that focused attention on how early adolescents experience school bullying as bystanders is particularly significant because most studies on bullying have emphasised and reported on only the experience of learners as bullies or as direct victims of bullying. The findings of this study confirmed that bullying can be described as a group phenomenon that involves the bystanders in addition to the bullies and the victims identified earlier in the literature. 
The findings of this study also revealed that witnesses of bullying behaviour can also be negatively affected emotionally, psychologically, and academically. All this might be helpful to teachers, school counsellors, and educational psychologists to help them comprehend fully the impacts and consequences of bullying on bystanders' emotions, cognition, and social adjustment when they are designing strategies to help victims of bullying and bystanders in school. As for the learner who bullies, the findings of this study might make them aware of the negative effect of bullying on the mental and physical health and on the emotional wellbeing of victims and bystanders with a view to foster a sense of empathy in them. The rudiments of social emotional training should be incorporated into the life orientation curriculum for learners in school. This will enable them to develop elementary collective empathy that might stop them from trivialising bullying incidents.

\section{Conclusion and recommendations}

The study contributes to the literature on bystanders of bullying. The bystander is relatively under-researched in the literature (Salmivali, 2014). One of the reasons why this is so may be because of the limited attempts at creating more collaborative engagements and this, of course, makes data on bystander experiences scarce. This study afforded some bystanders the opportunity to voice their experiences and reactions to witnessing bullying in school. The qualitative research approach used in this study gave bystanders the chance to give in-depth descriptions of their experiences of school bullying that might have been limited if the quantitative approach had been used.

Based on the findings of this study we recommend that future research studies should expand their scope by increasing the sample size and geographical coverage. We also recommend that teachers should teach potential bystanders to identify and practise positive behavioural techniques to mitigate the effect of witnessing bullying. Anti-bullying programs should be included in the curriculum so that teachers, school psychologists, and counsellors (if there are any in schools) would have the opportunity to highlight the emotional, psychological, and educational impact of bullying and emphasise to the learners that the consequences of bullying extend to all who are exposed to it.

\section{Acknowledgment}

We thank all the participants and the principal of the school where the study took place for cooperating with us before, during, and after data collection.

\section{Disclosure}

There is no conflict of interest. 


\section{References}

Adewoye, S. E., \& Du Plessis, A. (2021). Factors that influence emotional disturbance among school bullying bystanders. International Journal of Emotional Education, 13(1), 3550. https://www.um.edu.mt/library/oar/handle/123456789/76515

Bakken, N. W., \& Gunter, W. D. (2012). Self-cutting and suicidal ideation among adolescents: Gender differences in the causes and correlates of self-injury. Deviant Behaviour, 33, 339-356. https://doi.org/10.1080/01639625.2011.584054

Baldry, A. C., Farrington, D. P., \& Sorrentino, A. (2017). School bullying and cyberbullying among boys and girls: Roles and overlap. Journal of Aggression, Maltreatment, \& Trauma, 26(9), 937-951. https://doi.org/10.1080/10926771.2017.1330793

Barhight, L. R., Hubbard, J. A., \& Hyde, C. T. (2013). Children's physiological and emotional reactions to witnessing bullying predict bystander intervention. Child Development, 84, 375-390. https://doi: 10.1111/j.1467-8624.2012.01839

Basit, T. N. (2010). Conducting research in educational contexts. Continuum International Publishing Group.

Bender, D., \& Losel, F. (2011). Bullying at school as a predictor of delinquency, violence and other anti-social behaviour in adulthood. Criminal Behaviour \& Mental Health, 21, 99-106. https:// doi: 10.1002/cbm.799

Berkowitz, R., \& Benbenishty, R. (2012). Perceptions of teachers' support, safety, and absence from school because of fear among victims, bullies, and bully-victims. American Journal of Orthopsychiatry, 82, 67-74. http://doi.org/: 10.1111/j.19390025.2011.01132.x

Boyes, M. E., Bowes, L., Cluver, L. D., Ward, C. L., \& Badcock, N. A. (2014). Bullying victimisation, internalising symptoms, and conduct problems in South African children and adolescents: A longitudinal investigation. Journal of Abnormal Child Psychology, 42(8), 313-1324. http://doi.org/10.1007/s10802-014-9888

Bradshaw, C. P., Wasadrop, T. E., Goldweber, A., \& Johnson, S. L. (2013). Bullies, gangs, drugs and school: Understanding the overlap and the role of ethnicity and urbanity. Journal of Youth and Adolescents, 42(2), 220-234. https//doi: 10.1007/s10964-0129863-7

Braun, V., \& Clarke, V. (2006). Using thematic analysis in psychology. Qualitative Research in Psychology, 3, 77-101. https:// doi: 10.1191/1478088706qp063oa

Burton, E., \& Jones, D. (2008). Doing your education research project. Sage. 
Carrera, M. V., DePalma, R., \& Lameiras, M. (2011). Toward a more comprehensive understanding of bullying in school settings. Educational Psychology Review, 23(4), 479-499. https://doi.org/10.1007/s10648-011-9171-x

Creswell, J. W. (2014). Research design: qualitative, quantitative, mixed methods approaches. Sage.

Darney, C., Howcroft, G., \& Stroud, L. (2013). The impact that bullying at school has on an individual's self-esteem during young adulthood. International Journal of Education and Research, 1(8), 1-16.

Deng, X., Yang, J., \& Wu, Y. (2021). Adolescent empathy influences bystander defending in school bullying: A three-level meta-analysis. Frontiers in Psychology, 12, 690-898. https://doi: 10.3389/fpsyg.2021.690898

Englander, E. K. (2013). Bullying and cyber bullying: What every educator needs to know. Harvard Education Press.

Esala, J. E. (2013). Communities of denial: The co-construction of gendered adolescent violence. Deviant Behaviour, 34, 97-114. https://doi.org/10.1080/01639625.2012.707543

Gaffney, H., Ttofi, M. M., \& Farrington, D. P. (2021). Effectiveness of school-based programs to reduce bullying perpetration and victimization: An updated systematic review and meta-analysis. Campbell Systematic Reviews, 17, e1143. https://doi.org/10.1002/cl2.1143

Geel, M., Van Goemans, A., \& Vedder, P. H. (2016). The relation between peer victimization and sleeping problems: A meta-analysis. Sleep Medicine Reviews, 27, 89-95. https://doi.org/10.1016/j.smrv.2015.05.004

Gini, G., \& Pozzoli, T. (2013). Bullied children and psychosomatic problems: A metaanalysis. Pediatrics, 132, 720-729. https://doi.org/10.1542/peds.2013-0614

Holt, M. K., Vivolo-Kantor, A. M., Polanin, J. R., Holland, K. M., DeGue, S., Matjasko, J. L., Wolfe, M., \& Reid, G. (2015). Bullying and suicidal ideation and behaviours: A meta-analysis. Pediatrics, 135(2), e496-e509. https://doi.org/10.1542/peds.2014-1864

Howard, A. M., Landau, S., \& Pryor, J. B. (2014). Peer bystanders to bullying: Who wants to play with the victim? Journal of Abnormal Child Psychology, 42, 265-276. https:// doi: 10.1007/s10802-013-9770-8

Hutchinson, M. (2012). Exploring the impact of bullying on young bystanders. Educational Psychology in Practice, 28, 425-442. http://dx.doi.org/10.1080/02667363.2012.727785 
Juan, A., Zuze, L., Hannan, S., Govender, A., \& Reddy, V. (2018). Bullies, victims and bully-victims in South African schools: Examining the risk factors. South African Journal of Education, 38(1), 1-10. https://doi.org/10.15700/saje.v38ns1a1585

Knauf, R., Eschenbeck, H., \& Hock, M. (2018). Bystanders of bullying: Social-cognitive and affective reactions to school bullying and cyberbullying. Journal of Psychosocial Research on Cyberspace, 12(4), 1-17. https://doi.org/10.5817/CP2018-4-3

Laas, A., \& Boezaart, T. (2014). The legislative framework regarding bullying in South African schools. Potchefstroomse Elektroniese Regsblad, 17(6), 2667-2702. https://doi.org/10.4314/pelj:vl7i6.12

Lambe, L. J., Hudson, C. C., Craig, W. M., \& Pepler, D. J. (2017). Does defending come with a cost? Examining the psychosocial correlates of defending behaviour among bystanders of bullying in a Canadian sample. Child Abuse \& Neglect, 65, 112-123. https://doi.org/10.1016/j.chiabu.2017.01.012

Midgett, A., \& Doumas, D. M. (2019). Witnessing bullying at school: The association between being a bystander and anxiety and depressive symptoms. School Mental Health, 1-10. https://doi.org/10.1007/s12310-019-09312-6

Mncube, V., \& Chinyama, N. (2020). Learners' perspectives on bullying in South African schools. Journal of Human Ecology, 69(1/3), 38-51.

Modecki, K. L., Minchin, J., Harbaugh, A. G., Guerra, N. G., \& Runions, K. C. (2014). Bullying prevalence across contexts: A meta-analysis measuring cyber and traditional bullying. Journal of Adolescent Health, 55, 602-611. https://doi.org/10.1016/j.adohealth.2014.06.007

Moosa, M. (2020). From learner to teacher: Personal experiences, beliefs and attitudes about bullying victimisation. African Journal of Criminology \& Victimology, 33(2) 75-91.

Morgan, B., \& Pretorius, G. (2013). Choosing a topic. In J. G Maree (Ed.). Complete your thesis or dissertation successfully: Practical guidelines. Juta.

Padgett, S., \& Notar, C. E. (2013). Bystanders are the key to stopping bullying. Universal Journal of Educational Research, 1, 33-41. http://doi.org/10.13189/ujer.2013.010201

Polanin J. R., Espelage D. L., \& Pigott T. D. (2012). A meta-analysis of school-based bullying prevention programs' effects on bystander intervention behaviour. School Psychology Review, 41(1), 47-65. https://doi: 10.1080/02796015.2012.12087375

Rigby, K., \& Johnson, B. (2006). Expressed readiness of Australian school children to act as bystanders in support of children who are being bullied. Educational Psychology, 26, 425-440. http://doi/10.1080/01443410500342047 
Rivers, I., Poteat, V. P., Noret, N., \& Ashurst, N. (2009). Observing bullying at school: The mental health implications of witness status. School Psychology Quarterly, 24, 211223. https://doi.org/10.1037/a0018164

South African Human Rights Commission. (2008). Report on the public hearing on school based violence. South African Human Rights Commission.

Salmivalli, C (2014). Participant roles in bullying: How can peer bystanders be utilized in interventions? Theory into Practice, 53(4), 286-292. http://doi.org/10.1080/00405841.2014

Sefotho, M. M. (2018). Philosophy in education and research: African perspectives. Van Schaik Publishers

Silverman, D. (2011). Interpreting qualitative data (4th ed.). Sage.

Strom, I. F., Thoresen, S., Wentzel-Larsen, T., \& Dyb, G. (2013). Violence, bullying and academic achievement: A study of 15-year-old adolescents and their school environment. Child Abuse \& Neglect, 37(4), 243-251. https://doi.org/10.1016/j.chiabu.2012.10.010

Timm, V. M., \& Eskell-Blokland, L. M. (2011). A construction of bullying in a primary school in an underprivileged community: An ecological case study. South African Journal of Psychology, 41, 339-350. https://doi.org/10.1177/008124631104100308

Tsang, S. K., Hui, E. K., \& Law, B. C. (2011). Bystander position taking in school bullying: The role of positive identity, self-efficacy, and self-determination. Scientific World Journal, 11, 2278-2286. https://doi.org/10.1100/2011/531474

Ttofi, M. M., \& Farrington, D. P. (2011). Effectiveness of school-based programs to reduce bullying: A systematic and meta-analytic review. Journal of Experimental Criminology, 7, 27-56. https://doi.org/10.1007/s11292-010-9109-1

Ttofi, M. M., Farrington, D. P., \& Lösel, F. (2012). School bullying as a predictor of violence later in life: A systematic review and meta-analysis of prospective longitudinal studies. Aggression and Violent Behaviour, 17, 405-418. https://doi.org/10.1016/j.avb.2012.05.002

Ttofi, M. M., Farrington, D. P., Lösel, F., Crago, R. V., \& Theodorakis, N. (2016). School bullying and drug use later in life: A meta-analytic investigation. School Psychology Quarterly, 31(1), 8-27. https://doi.org/10.1037/spq0000120

Tustin, D. H., Zulu, G. N., \& Basson, A. (2014). Bullying among secondary school learners in South Africa with specific emphasis on cyber bullying. Child Abuse Research in South Africa, 15(2), 13-25. https://doi.org/10.15700/saje.v38ns1a1585 
Valdebenito, S., Eisner, M., Farrington, D. P., Ttofi, M. M., \& Sutherland, A. (2018). School-based interventions for reducing disciplinary school exclusion: A systematic review. Campbell Systematic Reviews, 1. https://doi.org/10.4073/csr.2018.1

Van Dam, D. S., Van der Ven, E., Velthorst, E., Selten, J. P., Morgan, C., \& De Haan, L. (2012). Childhood bullying and the association with psychosis in non-clinical and clinical samples: A review and meta-analysis. Psychological Medicine, 42, 24632474. https://doi: 10.1017/S0033291712000360.

Yin, R. K. (2016). Qualitative research from start to finish (2nd ed.). Guilford Press.

Zych, I., Farrington, D. P., Llorent, V. J., \& Ttofi, M. M. (2017). Protecting children against bullying and its consequences. Springer International Publishing. 